OPEN ACCESS

Edited by:

Jordi Giralt

Vall d'Hebron University Hospital, Spain

Reviewed by:

Edgar K. Selzer,

Medical University of Vienna, Austria Katrin Schröder,

University Hospital Frankfurt, Germany

${ }^{*}$ Correspondence: Tania Crombet Ramos taniac@cim.sld.cu

Specialty section: This article was submitted to Head and Neck Cancer, a section of the journa

Frontiers in Oncology

Received: 18 December 2019 Accepted: 27 April 2020 Published: 27 May 2020

Citation:

Crombet Ramos T, Mestre Fernández B, Mazorra Herrera Z and Iznaga Escobar NE (2020)

Nimotuzumab for Patients With Inoperable Cancer of the Head and

Neck. Front. Oncol. 10:817. doi: $10.3389 /$ fonc. 2020.00817

\section{Nimotuzumab for Patients With Inoperable Cancer of the Head and Neck}

\author{
Tania Crombet Ramos ${ }^{1 *}$, Braulio Mestre Fernández ${ }^{2}$, Zaima Mazorra Herrera ${ }^{1}$ and \\ Normando E. Iznaga Escobar ${ }^{3}$ \\ ${ }^{1}$ Center of Molecular Immunology, Havana, Cuba, ${ }^{2}$ Clinical Oncology, National Institute of Oncology and Radiobiology, \\ Havana, Cuba, ${ }^{3}$ Biocubafarma, Havana, Cuba
}

EGFR activation induces cell proliferation, neoformation of blood vessels, survival, and metastasis of the cancer cells. Nimotuzumab is an engineered, intermediate affinity anti-EGFR antibody, that apart from other drugs in its class, is very safe and does not cause hypomagnesemia or grade 3-4 cutaneous rash. The antibody inhibits cell proliferation and angiogenesis, activates natural killer cells, stimulates dendritic cell maturation, and induces cytotoxic T cells. Nimotuzumab restores MHC-I expression on tumor cells, hindering one of the EGFR immune-escape ways. The antibody has been extensively studied in 7 clinical trials, concurrently with irradiation or irradiation plus chemotherapy in subjects with inoperable head and neck tumors. Nimotuzumab was safe and efficacious in unfit patients receiving irradiation alone and in subjects treated with cisplatin and radiotherapy. In patients with locally advanced squamous cell carcinomas of the head and neck, nimotuzumab in combination with low dose cisplatin and radiotherapy was superior to cisplatin and radiotherapy in progression free survival, disease free survival, and locoregional tumor control.

Keywords: nimotuzumab, EGFR, monoclonal antibody, head and neck, radiotherapy

\section{INTRODUCTION}

Worldwide, squamous cell carcinomas of the head and neck (SCCHN) constitute the sixth in frequency and the ninth cause of death by cancer (1). The classic risk factors associated with the development of the disease are tobacco and alcohol consumption (2). Experts have estimated that the cancer risk in smokers is 3-15 times higher with respect to non-smokers and it is directly related to the duration of use and the onset of consumption (3). Globally, consumption of alcohol and tobacco causes nearly $65 \%$ of SCCHN $(4,5)$. Recently, viral infections with Epstein-Barr and human papilloma virus (HPV), have also been associated with the occurrence of head and neck neoplasms (6-8).

Surgery and radiotherapy (RT) are the classic therapeutic weapons employed in treating SCCHN $(9,10)$. Overall, both treatment modalities can be considered equally effective for small tumors. Larger tumors usually require the combined use of both treatment options (11). Curative-intent therapy of stage III or IV SCCHN patients requires a multimodal approach. For inoperable tumors, the preferred alternative is chemo-radiotherapy or radiotherapy plus monoclonal antibodies (MAbs) (12,13).

Despite the well-established effect in some patients, combined therapy induces adverse events like dermatitis, mucositis, and dysphagia. Treatment is also associated with hematologic 
toxicity, which augments the threat of hemorrhage or infection $(12,13)$. After therapy, quality of life is usually impaired because of late complications including sensorineural hearing loss, polyneuropathy, permanent xerostomia, and dysgeusia (14).

\section{EGFR IN TUMORIGENESIS}

Epidermal Growth Factor Receptor type I receptor (EGFR or HER 1) is an oncogene, member of the ErbB/HER family, with tyrosine-kinase activity in the intracellular domain (15, 16). The activation of the EGFR transduces a signal involving cell proliferation, inhibition of apoptosis, angiogenesis, and metastasis (16). EGFR overexpression is detected in $~ 90 \%$ of the $\operatorname{SCCHN}(17,18)$. A recent multivariate analysis demonstrated that overexpression of EGFR in subjects with stage II-IV head and neck neoplasms was associated with early relapses, lower disease-free, and overall survival $(19,20)$. Two types of molecules, small tyrosine-kinase inhibitors (STKI) and antibodies, have been developed to prevent EGFR signaling (20). Anti-EGFR MAbs recognize the extracellular region of the receptor, preventing activation by ligands $(20,21)$. Tumor cells destruction can also be mediated by antibody-dependent cell cytotoxicity (ADCC) or complement dependent-cytotoxicity (CDC) $(22,23)$. Alternatively, STKI bind to the intracytoplasmic domain of HER1, inhibiting its phosphorylation $(23,24)$.

\section{NIMOTUZUMAB MECHANISM OF ACTION}

Nimotuzumab is a humanized anti-EGFR MAb, which was obtained in 1996 after genetic modification of the parental murine molecule ior egf/r3 $(25,26)$. Nimotuzumab inhibits EGFR phosphorylation in several cell lines overexpressing this oncogene (27-34). The antibody has demonstrated significant antiproliferative, antiangiogenic, and pro-apoptotic activity in vitro and in tumor-engrafted mice (32).

In a glioma model, the antibody enhanced the radio-sensitivity by reducing the cancer stem cells (33). Recently, Mazorra and coworkers demonstrated that nimotuzumab activates natural killer (NK) cells, stimulates dendritic cell maturation and induces tumor-recognizing cytotoxic T-cells (34). Besides, the antibody restores MHC-I expression on tumor cells, hindering one of the EGFR immune-escape ways $(35,36)$.

Nimotuzumab recognition site at the extracellular domain of the EGFR was established by using phage display technology together with extensive mutagenesis of the EGFR and the Fab fragment of the antibody (37). The functional nimotuzumab epitope comprised a stretch of contiguous amino acids (S356-H359) and a non-contiguous residue (R353). Then, nimotuzumab interacting site was compared with the binding place of cetuximab, an approved antibody for the treatment of advanced head and neck cancer patients. The involvement of R353 located within the cetuximab structural epitope indicated some degree of overlapping between both epitopes and explains competition between the antibodies (37). Figure 1 shows the relative recognition sites of nimotuzumab and cetuximab at domain III of the EGFR.

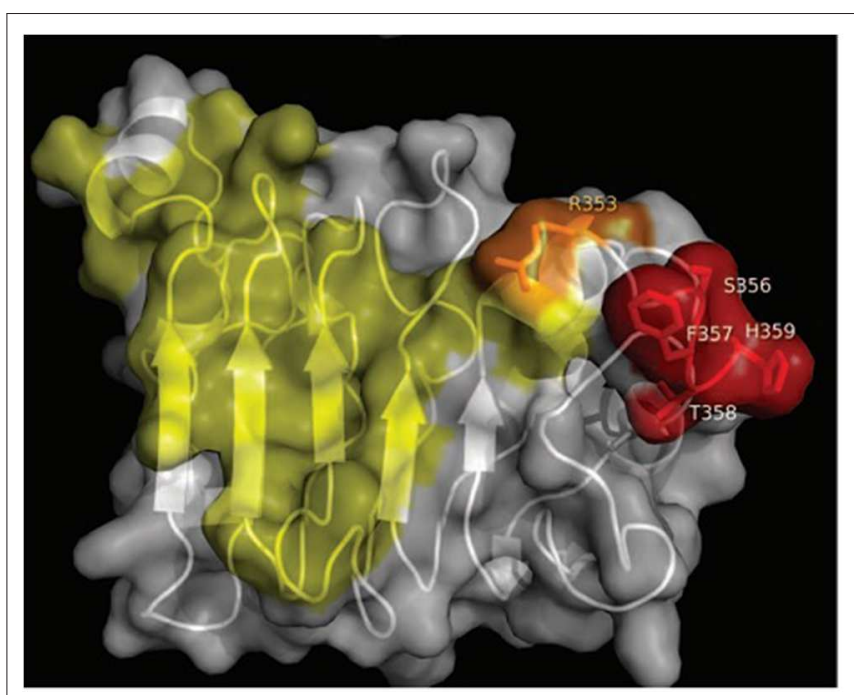

FIGURE 1 | Relative recognition sites of nimotuzumab and cetuximab at domain III of the EGFR. Residues recognized by cetuximab Fab fragment are colored in yellow, while residues recognized by nimotuzumab are colored in red. Overlapping recognition between nimotuzumab and cetuximab is colored in orange (figure reproduced with permissions of the authors).

According to a mathematical model developed by our group, antibodies with intermediate affinities like nimotuzumab, would have preferential accumulation in tumors with higher EGFR expression with respect to normal tissues (38). The mathematical model was composed of 4 differential equations reflecting the behavior of the antibody in 4 compartments (plasma, tumor, liver, and skin). Concentration-curves were obtained for each tissue by integrating the differential equations in time; the AUC was obtained by integrating equations again. AUC was assumed as a surrogate of the pharmacodynamic effect of the antibody in the referred tissue (38). The model explained that antibodies with higher affinity would recognize tumors with lower target expression, but also normal tissues (38). Several recent reports give support to this hypothesis (39-41). Akashi and cols. showed that binding of nimotuzumab and subsequent inhibition of the EGFR phosphorylation was detected only in tumor cell lines with medium or high EGFR expression $\left(10^{4}\right.$ receptors per cell or higher) (39). Furthermore, according to Garrido et al. binding of nimotuzumab Fab fragments was detected only in the A431 cell line $\left(10^{6}\right.$ receptors per cell), whereas cetuximab Fab fragments also bound to tumor cells with lower EGFR levels (40). As a consequence, higher affinity antibodies preserve efficacy even in those tumors with lower EGFR expression. These antibodies would also be more toxic, inducing on-target off-tumor toxicity such as skin rash and hypomagnesemia (42). For nimotuzumab, patients with high EGFR expression or gene amplification would have a larger benefit. Apart from the previous evidences in the preclinical (39-41) and clinical setting (43-52) on the correlation between EGFR expression and efficacy, this predictive biomarker should be further validated in prospective clinical trials. Table 1 compares the most important characteristic of nimotuzumab vs. cetuximab and panitumumb $(37,41,53)$ other marketing 
TABLE 1 | Comparison of nimotuzumab, cetuximab, and panitumumab on the main characteristics determining their biologic activity.

\begin{tabular}{|c|c|c|c|c|c|}
\hline Monoclonal antibody & Type & IgG subclass & Immune functions (ADCC) & Affinity (EGFR) & EGFR binding site in the EGF pocket \\
\hline Cetuximab & Chimeric & $\lg G 1$ & Yes & $\mathrm{KD}=10^{-10}$ & D355, Q408, H409, K443, S468 \\
\hline Panitumumab & Fully human & $\lg G 2$ & No & $\mathrm{KD}=10^{-11}$ & D355, K443 \\
\hline Nimotuzumab & Humanized & $\lg G 1$ & Yes & $\mathrm{KD}=10^{-9}$ & R353, S356, F357, T358, H359 \\
\hline
\end{tabular}

approved anti-EGFR MAbs for advanced head and neck and colorectal cancer.

\section{EARLY CLINICAL TRIALS}

Since 1998, more than 50 clinical trials have been concluded worldwide with nimotuzumab. A phase I study was done to characterize its safety and pharmacological properties (54). For antibodies like nimotuzumab, the optimal biologic dose is defined as the lowest dose at which there is a saturation of the systemic clearance, based on the assumption that zeroorder elimination is associated with the target saturation at the peripheral compartment (54). According to the Phase I pharmacokinetic data, $200 \mathrm{mg}$ was defined as the optimal biologic dose. The investigators concluded that the antibody was very safe at doses from 50 to $400 \mathrm{mg}$ (54). Apart from other molecules in its class, nimotuzumab does not provoke hypomagnesemia, diarrhea, severe cutaneous reactions or thromboembolic events, that are usually induced after the use of EGFR targeting MAbs or STKI (29). Nimotuzumab has been used in at least 7 completed clinical trials in patients bearing advanced SCCHN, concurrently with irradiation or chemo-radiotherapy. This paper summarizes the most important data obtained after adding the antibody to radiotherapy or radio/chemotherapy, according the evolving guidelines in patients with locally disseminated carcinomas.

In a phase I/II clinical trial, 4 individual doses including $50,100,200$, and $400 \mathrm{mg}$ of nimotuzumab (6 weekly doses), were evaluated (38). Combination therapy consisted of ionizing radiation in doses of $200 \mathrm{cGy}$ for 6 or 7 weeks to complete $6,000-7,200 \mathrm{~Gy}$ (38). In general, nimotuzumab was very welltolerated since no severe or very severe adverse reactions were reported. Most frequent nimotuzumab-related events comprised mild or moderate anorexia, chills, headache, fatigue, and fever (38). Most frequent events attributed to radiotherapy were mucositis, odynophagia, dry mouth, and radiodermitis (38). Authors concluded that there was no exacerbation of the irradiation associated toxicity after using nimotuzumab (38). Overall survival significantly increased with radiotherapy plus nimotuzumab at doses above $200 \mathrm{mg}$ compared to 50 and $100 \mathrm{mg}$ ( $p=0.03$ ) (38). Median survival of subjects treated with 200 or $400 \mathrm{mg}$ was 44,30 months and $66.7 \%$ of the patients were alive after 3 years (38). It is important to highlight that at the moment of the trial execution, locally advanced SCCHN patients received irradiation alone and not the combination of chemotherapy and radiotherapy, according the guidelines.

In a second single arm study, done at the Princess Margaret Hospital in Canada, nimotuzumab was evaluated together with irradiation. Eligible patients had newly diagnosed stage
III/IV SCCHN not amenable to surgery (55). Patients with distant metastases or serious comorbidities were excluded (55). Radiotherapy treatment consisted of 7,000 cGy in 35 fractions without concurrent chemotherapy (55). Nimotuzumab was administered at 100 or $200 \mathrm{mg}$, for 7 weeks (55). Twentyfour patients received the planned therapy. Most common side effects were grade 1 and 2 nausea, vomiting, headache, and fatigue (55). Of the 12 subjects evaluable for response in each cohort, 10 in the $100 \mathrm{mg}$ group and 11 in the $200 \mathrm{mg}$ group achieved complete or partial response, respectively (55). Authors concluded that nimotuzumab was well-tolerated by most patients and improved the response to radical radiotherapy in patients with SCCHN (55).

\section{PHARMACODYNAMIC DATA}

Pharmacodynamics was evaluated in 2 trials where nimotuzumab was used in combination with irradiation in the same population $(38,56)$. Proliferation was measured through the Ki67 nuclear antigen staining and angiogenesis was estimated using an anti-Von-Willebrand factor antibody. Proliferative activity declined significantly after 3 weekly doses of nimotuzumab (38). Similarly, tumor biopsies showed a remarkable decrease in blood vessels density (38). A second pharmacodynamic study was done in patients with inoperable SCCHN, unfit for concurrent radio and chemotherapy (56). Paired skin and tumor biopsies were obtained before and after the first nimotuzumab administration (56). Immunohistochemistry was used to assess the nimotuzumab impact on the signal transduction cascade on paired skin and tumor biopsies. EGFR expression (regardless the activation status) was not modified by the antibody, either on the skin or tumor biopsies (56). In the skin, p-EGFR (phosphorylated EGFR) in keratinocytes did not decrease after the use of nimotuzumab compared with pre-treatment biopsies (56). On the contrary, nimotuzumab was able to significantly inhibit the HER1 activation (phosphorylation) in the tumor samples (56).

\section{VACCINAL EFFECT}

Some monoclonal antibodies can exert anti-tumor effect by recruiting effector cells from the innate and adaptive immune system $(57,58)$.

In addition to the effect in the signal transduction cascade, the capacity of nimotuzumab of increasing the proportion of T-lymphocytes recognizing HER1 (EGFR) peptides in vivo was assessed in subjects with SCCHN (59). Peripheral blood mononuclear cells from patients receiving multiple doses of 
nimotuzumab were cultured with a pool of HER1 peptides. Interferon gamma (IFN $\gamma$ ) producing $\mathrm{T}$ lymphocytes were quantified by ELISpot and compared with nimotuzumab naïve patients. There was a significantly higher fraction of IFN $\gamma$ secreting $\mathrm{T}$ lymphocytes recognizing the EGFR peptides, in subjects with prolonged therapy with nimotuzumab (59). The vaccinal effect mechanism could be attributed to the stimulation of immunogenic apoptosis or the activation NK cells exerting antibody-dependent cell cytotoxicity (ADCC). NK cells trigger dendritic cells activation, that stimulate the HER1-recognizing T lymphocytes in subjects receiving repeated nimotuzumab doses $(34,59)$. In summary, aside from blocking EGFR or inducing tumor lysis through the NK cells, nimotuzumab induce specific memory $\mathrm{T}$ cells against the EGFR, responsible for long-lasting clinical responses.

Furthermore, the percentage of regulatory $\mathrm{T}$ cells (Tregs) significantly increased in these SCCHN patients after receiving radio-chemotherapy and nimotuzumab. However, the frequency of Tregs decreased to baseline values with nimotuzumab maintenance (59). Regulatory $\mathrm{T}$ cells constitute an important immune-escape mechanism of tumors (60). Authors concluded that nimotuzumab can exert a "vaccinal effect" and circumvent one of the tumors induced immunosuppression ways (59).

\section{RANDOMIZED STUDIES}

The first controlled trial enrolled 106 patients with advanced loco-regional SCCHN, not suitable to receive concurrent chemo-radiotherapy (43). Patients were randomized to receive irradiation plus nimotuzumab or placebo (43). In the experimental group, $70.37 \%$ of the enrolled subjects presented side events of any attribution while in the control arm, $57.69 \%$ of the patients receiving irradiation and placebo had adverse events (43). Nimotuzumab attributed reactions consisted primarily on grade 1 or 2 fatigue, fever, chills, headache, and appetite loss (43). Radiotherapy associated side reactions in both groups were mucositis, radiodermitis, odynophagia, and dry mouth (43). Authors concluded that nimotuzumab did not increase irradiation toxicity (43).

The trial endpoint was the assessment of response rate in both groups (43). Complete response rate was $59.5 \%$ in the antibody plus radiotherapy cohort vs. $34.2 \%$ in the control arm. Differences in complete response were statistically significant (43). Median overall survival was 12.50 vs. 9.47 months in the experimental and control groups (43). Median overall survival was lower than the expected for newly diagnosed subjects, provided the poor performance status and comorbidities of the enrolled population, which precluded treatment with concurrent chemo-radiotherapy (43). Differences in survival were significant according Harrington-Fleming, a highly sensitive test to detect differences deferred in time (43).

After the approval of chemo-radiotherapy as the recommended regimen for advanced SCCHN, nimotuzumab was combined with cisplatin-based chemotherapy and irradiation.

In a controlled study done in India leaded by the Kidwai Memorial Institute of Oncology in Bangalore, 92 stage III/IVA patients were randomly allocated to 2 groups: group A (radiation vs. radiation + nimotuzumab) and group B (chemo-radiotherapy vs. chemo-radiotherapy + nimotuzumab). Subjects received 6066 Gy in combination with 6 weekly antibody doses (61).

Chemotherapy consisted of cisplatin, $50 \mathrm{mg} /$ week for 6 weeks in group B (61). After the 3-agents combination, the most frequent toxicities were mild to moderate asthenia, dizziness, microscopic hematuria, vomiting, fever, chills, itching, skin rash, headache, and hypertension (61). In group A, the objective antitumor response was $76 \%$ in subjects who received radiation and nimotuzumab vs. $37 \%$, in patients receiving radiotherapy only (61). In group B, the rate of loco-regional control was $100 \%$ in patients receiving nimotuzumab plus chemo-radiation vs. $70 \%$ in patients treated with chemo-radiotherapy (61).

After long-term follow-up, the 5-year survival rate was 39\% with radiotherapy + nimotuzumab vs. $26 \%$ for radiotherapy alone $(p>0.05)$ (62). Survival rate was $57 \%$ for the chemo-radiotherapy-nimotuzumab group vs. $26 \%$ for chemoradiotherapy $(p=0.03)$, after 5 years $(62)$. The risk of death was $24 \%$ lower if patients received radiotherapy + nimotuzumab compared to radiotherapy alone while the death risk was $64 \%$ lower with chemo-radiotherapy + nimotuzumab compared to chemo-radiotherapy (62).

Recently, a phase III study designed to assess the impact of nimotuzumab plus cisplatin and irradiation in progression-free survival (PFS) was completed (63). Other goals of the study were the evaluation of disease-free survival, loco-regional control (LRC) and overall survival vs. cisplatin/irradiation. Safety and treatment completion of the regimen were also assessed (63). Five hundred thirty-six (536) subjects were enrolled in the phase III trial done at the Tata Memorial Hospital, in Mumbai, India (63). Selection criteria were age $>18$ years, confirmation of squamous carcinomas of the oral cavity, oropharynx, hypopharynx, or larynx, stage III-IV, and no distant metastasis. Patients had proper functioning of organs and systems and were fit to receive chemo-radiotherapy (63).

At the time of inclusion, the 2 cohorts were balanced in relation to the key demographic and tumor variables (63). Overall, most subjects showed a good performance status and the primary tumors were mainly from the oropharynx and larynx (63). More than 75\% of the patients carried bulky tumors (T3 or T4) and more than $50 \%$ of patients had N2 or N3 (52). A large proportion of patients (65\%) had stage IVA tumors at the time of recruitment. Remarkably, roughly $70 \%$ of the evaluated samples were HPV negative (63).

Patients were allocated to chemotherapy (weekly cisplatin 30 $\mathrm{mg} / \mathrm{m}^{2}$ dose, 7 weeks) + radiation therapy (total dose of 6,600$7,000 \mathrm{cGy})$ or the same treatment plus weekly nimotuzumab (200 mg/dose) to complete 7 doses (63). Overall, there was good adherence to chemotherapy and radiation. The median number of cisplatin cycles for both arms was 7 (63). More than $80 \%$ of the patients in both cohorts received 7 cycles of cisplatin and $<10 \%$ of subjects required cisplatin dose reduction (63). More than $75 \%$ of the patients received a total cisplatin dose $>200 \mathrm{mg} / \mathrm{m}^{2}$, comparable with the dose of cisplatin administered in the high-dose chemotherapy schemes (cisplatin $100 \mathrm{mg} / \mathrm{m}^{2}$ every 3 weeks) (63). Patients received 7 doses of nimotuzumab 
(median number of doses), according the planned scheme. No differences in treatment compliance were found, and researchers concluded that the use of nimotuzumab did not affect completion of cisplatin and irradiation (63).

Subjects receiving nimotuzumab together with cisplatin and radiotherapy had a significant and clinically meaningful advantage in PFS: 60.3 months (nimotuzumab group) vs. 21 months (control group) (HR $0.69 ; p=0.004)$ (52). The PFS rate at 2 -years was $61.8 \%$ (nimotuzumab arm) vs. $50.1 \%$ (control arm) (63). Subjects receiving an accumulative cisplatin dose $\geq 200$ $\mathrm{mg} / \mathrm{m}^{2}$ also had a better PFS (HR, $\left.0.73 ; p=0.036\right)$. The PFS HR for patients with oropharyngeal cancers that were p16-negative was 0.54 (63).

The differences in DFS were also significant (HR 0.71; $p=$ 0.008 ) (63). Two-year DFS was $60.2 \%$ (nimotuzumab group) vs. $48.5 \%$ (control). Nimotuzumab treated subjects also had better response rate. Two-year LRC was $67.5 \%$ (nimotuzumab arm) vs. $57.6 \%$ (control arm) (HR 0.67; $p=0.006)$ (63).

The adverse events frequency was similar in the 2 groups (63). Most common events were associated with the natural history of advanced head and neck disease and concurrent use of chemo and irradiation (63). Cutaneous rash was more frequent in those subjects receiving nimotuzumab plus chemo-radiation therapy (63). Despite the triple combination, only $17 \%$ of patients developed rash of any degree (63). The proportion of patients who developed grade 3-5 events did not differ in both arms of treatment, with the exception of mucositis. Grade 3-5 mucositis was more frequent in the experimental arm (63).

After the marketing approval of nimotuzumab in Cuba, a Phase IV study was conducted in 225 subjects (64). Newly diagnosed patients were treated with nimotuzumab plus irradiation and chemotherapy while unfit subjects for radio or chemotherapy had other treatment modalities (64). Cisplatin was administered every 21 days at a dose of $75-100 \mathrm{mg} / \mathrm{m}^{2}$ or weekly $\left(40 \mathrm{mg} / \mathrm{m}^{2}\right)$, according each patient performance status or comorbidities (64). One- and two-year PFS for those subjects receiving cisplatin, irradiation plus nimotuzumab was 67.3 and $46.3 \%$, respectively (64). For those treated with radiotherapy and nimotuzumab, 1 and 2-year PFS was 42.9 and 28.6\%, respectively (53). Most frequent events related to the antibody were nausea (25\%), neutropenia (13.9\%), anorexia (19.4\%), fever (11.1\%), anemia (13.9\%), asthenia (16.7\%), and vomiting (8.3\%). Adverse reactions were grade 1 or 2 and non-serious (64).

\section{HIGH DOSE CHEMOTHERAPY VS. LOW DOSE CHEMOTHERAPY FOR SCCHN}

Concurrent irradiation and chemotherapy is the recommended regimen for locally advanced SCCHN patients (65). The current standard protocol of chemo-radiotherapy, involves the use of radiotherapy concurrent with cisplatin bolus dose of $100 \mathrm{mg} / \mathrm{m}^{2}$ infused every 21 days (65). Despite the good results with this protocol, treatment-related toxicity remains an important concern. Unacceptable toxicity provokes a delay of the definitive radiotherapy, which, in turn, negatively affects the general therapeutic outcome, especially in elderly patients or in subjects with poor general conditions (65).

In the most recent studies, nimotuzumab was used in combination with low dose cisplatin and radiation (62-64).

There are many recent evidences, supporting the noninferiority of low cisplatin dose as compared to the high dose regimen. Evidences come from retrospective meta-analysis, systematic reviews or prospective randomized studies (6572). Mohamed and co-workers did a systematic review that contrasted adverse events and efficacy of once-a-week vs. every 3 -weeks cisplatin in stage III/IV SCCHN (66). Authors studied 1,500 trials reported between 1970 and 2015, of which, 39 studies were eligible for the research. Cisplatin weekly doses ranged from 30 to $40 \mathrm{mg} / \mathrm{m}^{2}$. Locoregional control was 58 vs. $61 \%(p=0.7)$, weekly vs. triweekly (66). Overall survival rate after 2 years was also similar: $74 \%$ (once-a-week) vs. $67 \%$ (every 3-weeks) ( $p=$ 0.67 ) (66). PFS rate at 24 months was 69 vs. $62 \%$ (once-a-week vs. every 3-weeks) $(p=0.9)(66)$. Authors concluded that both schemes were equivalent regarding clinical benefit (66).

Szturz et al., made a meta-analysis of 59 studies including more than 5,000 patients (67). For the conventional concurrent chemotherapy and irradiation, the high- and low-dose schemes had comparable survival (67). However, the 3-weekly protocol displayed greater hematology adverse reactions, nausea, vomiting and renal problems, typically cisplatin-related adverse events (67). Treatment compliance was better in the low dose vs. high dose regimen ( 88 vs. $71 \%, p=0.0017$ ) (67).

Guan and cols. did a meta-analysis of several trials comparing weekly low-dose to high-cisplatin dose every 3 weeks (68). In the study, which included 779 patients, survival was similar among the two groups. Subjects receiving weekly cisplatin had fewer gastrointestinal adverse effects but greater grade 3-5 mucositis (68).

Jacinto et al., made another meta-analysis of the published papers to evaluate the efficacy of cisplatin once-a-week vs. 3-weekly, in the definitive and adjuvant therapy of SCCHN patients (69). Seven studies were included in the review. Authors concluded that PFS and survival rate at 1 year were similar between the weekly and every 3 -weeks arms. The same results were confirmed after 5 years follow-up (69).

In another study, Bauml and cols, examined the outcome of patients with locally advanced SCCHN treated with concurrent irradiation and cisplatin at high-dose (HDC) or low-dose (LDC), using Veterans Affairs data across the United States (70). The research involved 2,901 subjects. After correcting for performance status, high dose did not improve overall survival (HR 0.94) (70). However, HDC groups had augmented risk of renal failure, leukopenia, and hearing damage (70).

Apart from these retrospective meta-analyses, Lee et al. did a prospective study including 220 South-Korean patients, of which 65 received cisplatin at a dose of $100 \mathrm{mg} / \mathrm{m}^{2}$ every 21 days while 155 subjects got cisplatin weekly doses of $30-40 \mathrm{mg} / \mathrm{m}^{2}$ (60). In this controlled study, median PFS of the weekly group was not different to the high dose group ( $p=0.81)$ (71). The 3-year overall survival and PFS were similar between the groups (71).

Helfenstein and collaborators in Switzerland conducted a prospective clinical trial where 314 patients were treated with 
weekly or tree-weekly cisplatin (72). Mean total dose was 200 $\mathrm{mg} / \mathrm{m}^{2}$ for subjects in the tree-weekly regimen and $160 \mathrm{mg} / \mathrm{m}^{2}$ in the weekly scheme. A cumulative cisplatin dose $\geq 200 \mathrm{mg} / \mathrm{m}^{2}$ did not translate into a survival benefit (72).

We conclude that alternative regimens with lower cisplatin dose reduce toxicity, permit good treatment completion and preserve antitumor effect. This was precisely the regimen selected for the recent nimotuzumab-controlled trial.

\section{CHEMO-RADIOTHERAPY COMBINED WITH OTHER ANTI-EGFR MONOCLONAL ANTIBODIES}

Cetuximab had shown efficacy in the treatment of recurrent or metastatic head and neck tumors (73). However, for newly diagnosed advanced patients with PS of $0-1$, the recommended treatment is concurrent systemic therapy with cisplatin or carboplatin and radiotherapy (74). Cetuximab can also be recommended in combination with radiotherapy for the systemic treatment of locally advanced head and neck cancer (74). In the Bonner trial, 424 patients with locally advanced stage III/IV squamous cell carcinomas of the hypopharynx, oropharynx and larynx received definitive RT with or without cetuximab (75). Median survival time was 49 vs. 29.3 months (75). The trial included mainly patients with oropharyngeal tumors (60\%) (75). In a secondary analysis of the trial including only patients with larynx or hypopharynx tumors, there were no differences in laryngeal preservation, laryngectomy free survival, and overall survival (65). In general, the combination of cetuximab and radiotherapy is prescribed to patients unfit to receive cisplatin and radiotherapy, provided that several trials, mainly done in the scenario of HPV positive oropharynx cancer, demonstrated that cetuximab/RT was inferior to cisplatin/RT (76-78).

Two clinical trials with the anti-HER1 MAbs cetuximab and panitumumab, failed in augmenting the effect of radiotherapy plus high-dose cisplatin in SCCHN patients with stage III/IV tumors $(79,80)$.

RTOG 0522 was a Phase III study that test the hypothesis that adding cetuximab to radiotherapy-cisplatin $\left(100 \mathrm{mg} / \mathrm{m}^{2}\right)$ improves PFS (79). Locally advanced SCCHN patients were treated with cisplatin/irradiation with or without cetuximab (79). The addition of cetuximab did not increase PFS, overall survival, loco-regional control, or distant metastasis (79). The regimen caused more serious adverse effects, which had a negative impact on the radiotherapy compliance, neutralizing any potential benefit in tumor control (79). There were more treatment related deaths and grade 3-4 events including rash, fatigue, anorexia, hypokalemia, as well as more acute radiation mucositis in the cetuximab cohort (79). Authors concluded that adding cetuximab to the standard treatment of radiation-cisplatin did not improve the clinical benefit, had worse treatment compliance and greater toxicity (79). Table 2 compares nimotuzumab and cetuximab phase III clinical trials in combination with chemotherapy and radiotherapy for the treatment of locally advanced head and neck cancer.
TABLE 2 | Comparison between nimotuzumab and cetuximab Phase III clinical trials in combination with chemotherapy and radiotherapy for the treatment of locally advanced head and neck cancer.

\begin{tabular}{|c|c|c|}
\hline & Nimotuzumab SCCHN/2010 & Cetuximab RTOG0522 \\
\hline $\begin{array}{l}\text { Number of } \\
\text { patients }\end{array}$ & $\begin{array}{l}536 \text { newly diagnosed, stage III or } \\
\text { IV locally advanced squamous } \\
\text { cell carcinomas from the } \\
\text { oropharynx, larynx, } \\
\text { hypopharynx, or oral cavity }\end{array}$ & $\begin{array}{l}891 \text { stage III or IV (T2N2-3M0 or } \\
\text { T3-4, any N, M0) squamous cell } \\
\text { carcinoma of the oropharynx, } \\
\text { hypopharynx, or larynx }\end{array}$ \\
\hline $\begin{array}{l}\text { Primary } \\
\text { endpoint }\end{array}$ & Progression free survival & Progression free survival \\
\hline $\begin{array}{l}\text { P16 } \\
\text { positivity }\end{array}$ & $11.3 \%$ & $73.2 \%$ \\
\hline $\begin{array}{l}\text { Treatment } \\
\text { schedule }\end{array}$ & $\begin{array}{l}\text { Cisplatin dose: } 30 \mathrm{mg} / \mathrm{m}^{2} \text {, } \\
\text { weekly } \\
\text { RT dose: } 70 \text { Gy } \\
\text { Nimotuzumab dose: } 200 \mathrm{mg} \text {, } \\
\text { weekly for } 7 \text { weeks }\end{array}$ & $\begin{array}{l}\text { Cisplatin dose: } 100 \mathrm{mg} / \mathrm{m}^{2} \text {, on } \\
\text { days } 1 \text { and } 22 \text { of RT. } \\
\text { RT dose: } 70-72 \mathrm{~Gy} \text {. } \\
\text { Cetuximab dose: } 400 \mathrm{mg} / \mathrm{m}^{2} \\
\text { (induction), then } 250 \mathrm{mg} / \mathrm{m}^{2} \\
\text { weekly for } 7 \text { weeks. }\end{array}$ \\
\hline $\begin{array}{l}\text { Treatment } \\
\text { compliance }\end{array}$ & $\begin{array}{l}\text { No differences in radiotherapy } \\
\text { interruption between arms. } \\
\text { Radiotherapy interruptions as a } \\
\text { result of toxicity was } 4.5 \% \text { in the } \\
\text { nimotuzumab arm vs. } 3.7 \% \text { in } \\
\text { the control arm. }\end{array}$ & $\begin{array}{l}\text { Radiotherapy interruption as a } \\
\text { result of toxicity was significantly } \\
\text { higher in the cetuximab vs. } \\
\text { control arm ( } 26.9 \text { vs. } 15.1 \%) \\
p<0.001)\end{array}$ \\
\hline $\begin{array}{l}\text { MAB } \\
\text { doses }\end{array}$ & $\begin{array}{l}84.3 \% \text { received } 7 \text { or more } \\
\text { weekly nimotuzumab doses }\end{array}$ & $\begin{array}{l}73.6 \% \text { received } 6 \text { or more } \\
\text { weekly cetuximab doses }\end{array}$ \\
\hline Efficacy & $\begin{array}{l}\text { Significant improvement in PFS, } \\
\text { locoregional control, and } \\
\text { disease-free survival with } \\
\text { nimotuzumab. } \\
\text { Trend toward improved survival. }\end{array}$ & $\begin{array}{l}\text { No significant differences } \\
\text { between arms in PFS, overall } \\
\text { survival, locoregional failure, or } \\
\text { distant metastases. }\end{array}$ \\
\hline Safety & $\begin{array}{l}\text { Grade } 3-5 \text { adverse events were } \\
\text { similar between the } 2 \text { arms, } \\
\text { except for a higher incidence of } \\
\text { mucositis in the nimotuzumab } \\
\text { vs. control arm ( } 66.7 \text { vs. } 55.8 \% \text {; } \\
p=0.01 \text { ). } \\
\text { No differences in the treatment } \\
\text { related deaths }\end{array}$ & $\begin{array}{l}\text { Cetuximab arm had significantly } \\
\text { higher rates of grade } 3-4 \text { skin } \\
\text { reactions, radiation mucositis, } \\
\text { fatigue, anorexia, and } \\
\text { hypokalemia up to } 90 \text { days from } \\
\text { the start of therapy. } \\
\text { More treatment-related grade } 5 \\
\text { adverse events in the cetuximab } \\
\text { arm }(p=0.05) \text {. }\end{array}$ \\
\hline
\end{tabular}

In Concert 1, 153 subjects with stage III, IVa, or IVb SCCHN were allocated to chemoradiotherapy or panitumumab plus chemoradiotherapy (80). The main variable of the study was the 2-year LRC while secondary endpoints were PFS and overall survival (80). No differences were found in loco-regional control, PFS and survival between the 2 arms (80). Severe and very severe adverse reactions (dysphagia, mucosal inflammation, and radiodermitis) were more frequent in the panitumumab group. Authors did not recommend adding panitumumab to irradiation and cisplatin for treating SCCHN patients (80).

\section{CONCLUDING REMARKS}

Head and neck squamous cancer encompasses a great variety of tumors originating in the oral cavity, oropharynx, hypopharynx, lip, nasopharynx, or larynx. A large proportion of patients with SCCHN debuts with a tumor at locally advanced stage (11). 
These patients require a multidisciplinary care. In this scenario, chemo-radiotherapy is the standard approach $(9,12)$.

EGFR expression has been linked to radio-resistance of head and neck tumors $(81,82)$. Consequently, molecular targeting of EGFR for radio-sensitization stays as a very appealing strategy.

Nimotuzumab is a genetically engineered MAb with an intermediate affinity against the EGFR. Nimotuzumab is the safest antibody in its class since it selectively targets those tumor cells with a high expression of the receptor, while not binding to normal tissues. This is precisely the case of SCCHN, that exhibit a very high receptor expression. The distinctive effect in tumor and normal tissues is demonstrated by the low incidence of skin rash together with good antitumor activity. A different pharmacodynamic effect was confirmed when comparing serial tumor and skin biopsies: nimotuzumab was able to abrogate signal transduction in the tumor but not in the keratinocytes.

Besides inhibiting the signal transduction cascade, nimotuzumab behaves as an active immunotherapy, inducing EGFR specific $\mathrm{T}$ cells and reducing the Tregs. These immunomodulatory properties can explain the antibody long-lasting effect.

This review summarizes the results of seven single-arm or randomized clinical trials, where nimotuzumab was combined with radiotherapy or radiation and cisplatin. Collectively, these data support the effectiveness of HER1 inhibition with

\section{REFERENCES}

1. Vigneswaran N, Williams MD. Epidemiologic trends in head and neck cancer and aids in diagnosis. Oral Maxillofac Surg Clin North Am. (2014) 26:12341. doi: 10.1016/j.coms.2014.01.001

2. Beynon RA, Lang S, Schimansky S, Penfold CM, Waylen A, Thomas SJ, et al. Tobacco smoking and alcohol drinking at diagnosis of head and neck cancer and all-cause mortality: results from head and neck 5000, a prospective observational cohort of people with head and neck cancer. Int J Cancer. (2018) 143:1114-27. doi: 10.1002/ijc.31416

3. Shingler E, Robles LA, Perry R, Penfold C, Ness AR, Thomas S, et al. Systematic review evaluating randomized controlled trials of smoking and alcohol cessation interventions in people with head and neck cancer and oral dysplasia. Head Neck. (2018) 40:1845-53. doi: 10.1002/hed. 25138

4. Bover Manderski MT, Black K, Udasin IG, Giuliano AR, Steinberg MB, Ohman Strickland P, et al. Risk factors for head and neck cancer in the world trade center health program general responder cohort: results from a nested case-control study. Occup Environ Med. (2019) 76:85460. doi: 10.1136/oemed-2019-105890

5. Vannimenus C, Bricout H, Le Rouzic O, Mouawad F, Chevalier D, Dansin E, et al. Compared characteristics of current vs. past smokers at the time of diagnosis of a first-time lung or head and neck cancer: a crosssectional study. BMC Cancer. (2018) 18:372. doi: 10.1186/s12885-0184253-5

6. Ooft ML, van Ipenburg J, van de Loo RJM, de Jong R, Moelans CB, de Bree $\mathrm{R}$, et al. Differences in cancer gene copy number alterations between epstein-Barr virus-positive and epstein-Barr virus-negative nasopharyngeal carcinoma. Head Neck. (2018) 40:1986-98. doi: 10.1002/hed. 25195

7. Shui CY, Li C, Liu W, Cai YC, Jiang J, Sun RH, et al. Research progress in pathogenesis, treatment and prognosis of HPV positive head and neck squamous cell carcinoma. Zhonghua Er Bi Yan Hou Tou Jing Wai Ke Za Zhi. (2018) 53:392-6. doi: 10.3760/cma.j.issn.1673-0860.2018.05.014 nimotuzumab in the curative management of stage III/IV tumors from the oral cavity, oropharynx, hypopharynx, and larynx.

\section{AUTHOR CONTRIBUTIONS}

TC and NI participated in the design of the clinical trials done in Cuba. ZM characterized the mechanism of action of nimotuzumab in terms of inducing cellular immunity. BM participated as a clinical researcher in some of the studies, as a KOL from the Cuban Institute of Oncology and Radiobiology. All authors reviewed the published literature on nimotuzumab and the final manuscript.

\section{FUNDING}

The trials presented here-in were funded by the Center of Molecular Immunology, Cuba, the Cuban Ministry of Public Health, YMBiosciences (Canada)/Innocimab (Singapore), Biocon LTD (India) and the TATA Memorial Center Research Administration Council (India).

\section{ACKNOWLEDGMENTS}

We thank the head and neck cancer patients and their relatives, whoparticipated in the nimotuzumab clinical trials.

8. Antonsson A, Knight L, Panizza BJ, Porceddu SV, Emmett S, Whiteman DC. HPV-16 viral load in oropharyngeal squamous cell carcinoma using digital PCR. Acta Otolaryngol. (2018) 138:843-7. doi: 10.1080/00016489.2018.1461239

9. Iocca O, Farcomeni A, Di Rocco A, Di Maio P, Golusinski P, Pardiñas López $\mathrm{S}$, et al. Locally advanced squamous cell carcinoma of the head and neck: a systematic review and Bayesian network meta-analysis of the currently available treatment options. Oral Oncol. (2018) 80:4051. doi: 10.1016/j.oraloncology.2018.03.001

10. Mazzola R, Fiorentino A, Ricchetti F, Gregucci F, Corradini S, Alongi F. An update on radiation therapy in head and neck cancers. Expert Rev Anticancer Ther. (2018) 18:359-64. doi: 10.1080/14737140.2018.1 446832

11. Klausner G, Troussier I, Blais E, Carsuzaa F, Zilli T, Miralbell R, et al. Neck management in head and neck squamous cell carcinomas: where do we stand? Med Oncol. (2019) 36:40. doi: 10.1007/s12032-0191265-1

12. Amanam I, Gupta R, Mita A, Scher K, Massarelli E. Perspectives in head and neck medical oncology. Cancer Treat Res. (2018) 174:16385. doi: 10.1007/978-3-319-65421-8_10

13. Kozakiewicz P, Grzybowska-Szatkowska L. Application of molecular targeted therapies in the treatment of head and neck squamous cell carcinoma. Oncol Lett. (2018) 15:7497-505. doi: 10.3892/ol.2018.8300

14. Siddiqui F, Movsas B. Management of radiation toxicity in head and neck cancers. Semin Radiat Oncol. (2017) 27:3409. doi: 10.1016/j.semradonc.2017.04.008

15. Di Marco E, Pierce JH, Fleming TP, Kraus MH, Molloy CJ, Aaronson SA. Autocrine interaction between TGF alpha and the EGF-receptor: quantitative requirements for induction of the malignant phenotype. Oncogene. (1989) 4:831-8.

16. Mendelsohn J, Baselga J. Epidermal growth factor receptor targeting in cancer. Semin Oncol. (2006) 33:369-85. doi: 10.1053/j.seminoncol.2006.04.003

17. Weber RS, Pathak S, Frankenthaler R, Gallick GE, Sacks PG. Effect of epidermal growth factor (EGF) on a newly established head and neck 
squamous carcinoma cell line. Otolaryngol Head Neck Surg. (1988) 99:56773. doi: $10.1177 / 019459988809900605$

18. Kim BJ, Jeong JH, Kim HS, Kim JH. The role of anti-EGFR agents in patients with locoregionally advanced head and neck cancer: a meta-analysis of randomized trials. Oncotarget. (2017) 8:10237180. doi: 10.18632 /oncotarget. 21987

19. Santini J, Formento JL, Francoual M, Milano G, Schneider M, Dassonville O. Characterization, quantification, and potential clinical value of the epidermal growth factor receptor in head and neck squamous cell carcinomas. Head Neck. (1991) 13:132-9. doi: 10.1002/hed.2880 130209

20. Concu R. Cordeiro MNDS looking for new inhibitors for the epidermal growth factor receptor. Curr Top Med Chem. (2018) 18:219-32. doi: 10.2174/1568026618666180329123023

21. Xu MJ, Johnson DE, Grandis JR. EGFR-targeted therapies in the post-genomic era. Cancer Metastasis Rev. (2017) 36:463-73. doi: 10.1007/s10555-017-9687-8

22. Trivedi A, Stienen S, Zhu M, Li H, Yuraszeck T, Gibbs J, et al. Clinical pharmacology and translational aspects of bispecific antibodies. Clin Transl Sci. (2017) 10:147-62. doi: 10.1111/cts.12459

23. Moreira J, Tobias A, O’Brien MP, Agulnik M. Targeted therapy in head and neck cancer: an update on current clinical developments in epidermal growth factor receptor-targeted therapy and immunotherapies. Drugs. (2017) 77:843-57. doi: 10.1007/s40265-017-0734-0

24. Gold KA, Kies MS, William WN Jr, Johnson FM, Lee JJ, Glisson BS. Erlotinib in the treatment of recurrent or metastatic cutaneous squamous cell carcinoma: a single-arm phase 2 clinical trial. Cancer. (2018) 124:2169273. doi: $10.1002 /$ cncr. 31346

25. Mateo C, Moreno E, Amour K, Lombardero J, Harris W, Pérez R. Humanization of a mouse monoclonal antibody that blocks the epidermal growth factor receptor: recovery of antagonistic activity. Immunotechnology. (1997) 3:71-81. doi: 10.1016/S1380-2933(97)00065-1

26. Morales AA, Ducongé J, Alvarez-Ruiz D, Becquer-Viart ML, Núñez-Gandolff G, Fernández E, et al. Humanized versus murine anti-human epidermal growth factor receptor monoclonal antibodies for immunoscintigraphic studies. Nucl Med Biol. (2000) 27:199-206. doi: 10.1016/S0969-8051(99)00094-3

27. Viloria-Petit A, Crombet T, Jothy S, Hicklin D, Bohlen P, Schlaeppi JM, et al. Acquired resistance to the antitumor effect of epidermal growth factor receptor-blocking antibodies in vivo: a role for altered tumor angiogenesis. Cancer Res. (2001) 61:5090-10.

28. Diaz Miqueli A, Blanco R, Garcia B, Badia T, Batista AE, Alonso R, et al. Biological activity in vitro of anti-epidermal growth factor receptor monoclonal antibodies with different affinities. Hybridoma. (2007) 26:4233. doi: $10.1089 /$ hyb. 2007.0516

29. Perez R, Moreno E, Garrido G, Crombet T. EGFR-targeting as a biological therapy: understanding nimotuzumab's clinical effects. Cancers. (2011) 3:2014-31. doi: 10.3390/cancers3022014

30. Qu YY, Hu SL, Xu XY, Wang RZ, Yu HY, Xu JY, et al. Nimotuzumab enhances the radiosensitivity of cancer cells in vitro by inhibiting radiation-induced DNA damage repair. PLoS ONE. (2013) 8:e70727. doi: 10.1371/journal.pone.0070727

31. Diaz A, Batista AE, Montero E. Interferon-alpha conditioned sensitivity to an anti-epidermal growth factor receptor monoclonal antibody in a human lung cancer cell line with intermediate expression of the receptor. J Interferon Cytokine Res. (2009) 29:433-40. doi: 10.1089/jir.2008.0079

32. Crombet-Ramos T, Rak J, Pérez R, Viloria-Petit A. Antiproliferative, antiangiogenic and proapoptotic activity of h-R3: a humanized antiEGFR antibody. Int $J$ Cancer. (2002) 101:567-75. doi: 10.1002/ijc. 10647

33. Diaz-Miqueli A, Martinez GS. Nimotuzumab as a radiosensitizing agent in the treatment of high grade glioma: challenges and opportunities. Onco Targets Ther. (2013) 6:931-42. doi: 10.2147/OTT.S33532

34. Mazorra Z, Lavastida A, Concha-Benavente F, Valdés A, Srivastava RM, García-Bates TM, et al. Nimotuzumab induces NK cell activation, cytotoxicity, dendritic cell maturation and expansion of egfr-specific $\mathrm{t}$ cells in head and neck cancer patients. Front Pharmacol. (2017) 8:382. doi: 10.3389/fphar.2017.00382
35. Garrido G, Rabasa A, Sánchez B. Linking oncogenesis and immune system evasion in acquired resistance to EGFR-targeting antibodies: lessons from a preclinical model. Oncoimmunology. (2013) 2:e26904. doi: $10.4161 /$ onci.26904

36. Garrido G, Rabasa A, Garrido C, López A, Chao L, García-Lora AM, et al. Preclinical modeling of EGFR-specific antibody resistance: oncogenic and immune-associated escape mechanisms. Oncogene. (2014) 33:312939. doi: $10.1038 /$ onc. 2013.288

37. Tundidor Y, García-Hernández CP, Pupo A, Cabrera Infante Y, Rojas G. Delineating the functional map of the interaction between nimotuzumab and the epidermal growth factor receptor. MAbs. (2014) 6:1013-25. doi: 10.4161/mabs.28915

38. Crombet T, Osorio M, Cruz T, Roca C, del Castillo R, Mon R, et al. Use of the humanized anti-epidermal growth factor receptor monoclonal antibody h-R3 in combination with radiotherapy in the treatment of locally advanced head and neck cancer patients. J Clin Oncol. (2004) 22:164654. doi: $10.1200 / J C O .2004 .03 .089$

39. Akashi Y, Okamoto I, Iwasa T, Yoshida T, Suzuki M, Hatashita E, et al. Enhancement of the antitumor activity of ionising radiation by nimotuzumab, a humanised monoclonal antibody to the epidermal growth factor receptor, in non-small cell lung cancer cell lines of differing epidermal growth factor receptor status. Br J Cancer. (2008) 98:749-55. doi: 10.1038/sj.bjc.6 604222

40. Garrido G, Tikhomirov IA, Rabasa A, Yang E, Gracia E, Iznaga N, et al. Bivalent binding by intermediate affinity of nimotuzumab: a contribution to explain antibody clinical profile. Cancer Biol Ther. (2011) 11:37382. doi: $10.4161 /$ cbt.11.4.14097

41. Chao L, Pérez D, Sánchez B. Nimotuzumab-mediated antibody-dependent cellular cytotoxicity activity on target tumor cell lines depends on the expression level of the epidermal growth factor receptor. Biotecnol Aplicada. (2017) 34:1201-5.

42. Berger MD, Lenz HJ. The safety of monoclonal antibodies for treatment of colorectal cancer. Expert Opin Drug Saf. (2016) 15:799-80. doi: 10.1517/14740338.2016.1167186

43. Rodríguez MO, Rivero TC, del Castillo Bahi R, Muchuli CR, Bilbao MA, Vinageras EN, et al. Nimotuzumab plus radiotherapy for unresectable squamous-cell carcinoma of the head and neck. Cancer Biol Ther. (2010) 9:343-9. doi: 10.4161/cbt.9.5.10981

44. Lu Y, Chen D, Liang J, Gao J, Luo Z, Wang R, et al. Administration of nimotuzumab combined with cisplatin plus 5-fluorouracil as induction therapy improves treatment response and tolerance in patients with locally advanced nasopharyngeal carcinoma receiving concurrent radiochemotherapy: a multicenter randomized controlled study. BMC Cancer. (2019) 19:1262. doi: 10.1186/s12885-0196459-6

45. Du XJ, Li XM, Cai LB, Sun JC, Wang SY, Wang XC, et al. Efficacy and safety of nimotuzumab in addition to radiotherapy and temozolomide for cerebral glioblastoma: a phase II multicenter clinical trial. J Cancer. (2019) 10:3214-23. doi: 10.7150/jca.30123

46. Mao L, Tan J, Wang F, Luo Y, Liu W, Zeng F, et al. Retrospective study comparing anti-EGFR monoclonal antibody plus cisplatinbased chemoradiotherapy versus chemoradiotherapy alone for stage II-IVb nasopharyngeal carcinoma and prognostic value of EGFR and VEGF expression. Clin Otolaryngol. (2019) 44:572-80. doi: 10.1111/coa. 13340

47. Si X, Wu S, Wang $H$, Zhang $X$, Wang $M$, Zeng $X$, et al. Nimotuzumab combined with chemotherapy as first-line treatment for advanced lung squamous cell carcinoma. Thorac Cancer. (2018) 9:1056-61. doi: 10.1111/1759-7714.12789

48. Wang CY, Deng JY, Cai XW, Fu XL, Li Y, Zhou XY, et al. High EGFR and low p-Akt expression is associated with better outcome after nimotuzumab-containing treatment in esophageal cancer patients: preliminary clinical result and testable hypothesis. Oncotarget. (2015) 6:18674-82. doi: 10.18632/oncotarget.4367

49. Satoh T, Lee KH, Rha SY, Sasaki Y, Park SH, Komatsu Y, et al. Randomized phase II trial of nimotuzumab plus irinotecan versus irinotecan alone as second-line therapy for patients with advanced 
gastric cancer. Gastric Cancer. (2015) 18:824-32. doi: 10.1007/s10120-0140420-9

50. Ramos-Suzarte M, Lorenzo-Luaces P, Lazo NG, Perez ML, Soriano JL, Gonzalez CE, et al. Treatment of malignant, non-resectable, epithelial origin esophageal tumours with the humanized anti-epidermal growth factor antibody nimotuzumab combined with radiation therapy and chemotherapy. Cancer Biol Ther. (2012) 13:600-5. doi: 10.4161/cbt. 19849

51. Basavaraj C, Sierra P, Shivu J, Melarkode R, Montero E, Nair P. Nimotuzumab with chemoradiation confers a survival advantage in treatment-naïve head neck tumors over expressing EGFR. Cancer Biol Ther. (2010). 10:67381. doi: $10.4161 /$ cbt.10.7.12793

52. Okamoto W, Yoshino T, Takahashi T, Okamoto I, Ueda S, Tsuya A, et al. A phase I, pharmacokinetic and pharmacodynamic study of nimotuzumab in Japanese patients with advanced solid tumors. Cancer Chemother Pharmacol. (2013) 72:1063-71. doi: 10.1007/s00280-0132277-8

53. García-Foncillas J, Sunakawa Y, Aderka D, Wainberg Z, Ronga P, Witzler P, et al. Distinguishing features of cetuximab and panitumumab in colorectal cancer and other solid tumors. Front Oncol. (2019) 9:849. doi: 10.3389/fonc. 2019.00849

54. Crombet $\mathrm{T}$, Torres L, Neninger E, Catalá M, Solano ME, Perera A, T, et al. Pharmacological evaluation of humanized anti-epidermal growth factor receptor, monoclonal antibody h-R3, in patients with advanced epithelial-derived cancer. $J$ Immunother. (2003) 26:139-48. doi: 10.1097/00002371-20030300000006

55. Nabid A, Gamguly P, Venkatesan V, Schneider K, Sicheri D, MacKinnon J. A phase I dose escalation study of a humanized monoclonal antibody to EGFR (hR3) in patients with locally advanced squamous cell cancer of the head and neck (SCCHN) treated with radiotherapy (RT). Proc Am Soc Clin Oncol. (2002) 21. doi: 10.1016/S0360-3016(02)0 3557-5

56. Rojo F, Gracias E, Villena N, Cruz T, Corominas JM, Corradino I, et al. Pharmacodynamic trial of nimotuzumab in unresectable squamous cell carcinoma of the head and neck: a SENDO foundation study. Clin Cancer Res. (2010) 16:2474-82. doi: 10.1158/1078-0432.CCR-0 9-3042

57. Abès R, Gélizé E, Fridman WH, Teillaud JL. Long-lasting antitumor protection by anti-CD20 antibody through cellular immune response. Blood. (2010) 116:926-34. doi: 10.1182/blood-2009-10-2 48609

58. Wittrup KD. Antitumor antibodies can drive therapeutic $\mathrm{T}$ cell responses. Trends Cancer. (2017) 3:615-20. doi: 10.1016/j.trecan.2017. 07.001

59. Mazorra Z, Chao L, Lavastida A, Sanchez B, Ramos M, Iznaga N. Nimotuzumab: beyond the EGFR signaling cascade inhibition. Semin Oncol. (2018) 45:18-26. doi: 10.1053/j.seminoncol.2018. 04.008

60. Elkord E, Alcantar-Orozco EM, Dovedi SJ, Tran DQ, Hawkins RE, Gilham DE. T regulatory cells in cancer: recent advances and therapeutic potential. Expert Opin Biol Ther. (2010) 10:157386. doi: 10.1517/14712598.2010.529126

61. Ramakrishnan MS, Eswaraiah A, Crombet T, Piedra P, Saurez G, Iyer H, et al. Nimotuzumab, a promising therapeutic monoclonal for treatment of tumors of epithelial origin. MAbs. (2009) 1:41-8. doi: 10.4161/mabs.1. 1.7509

62. Reddy BK, Lokesh V, Vidyasagar MS, Shenoy K, Babu KG, Shenoy A, et al. Nimotuzumab provides survival benefit to patients with inoperable advanced squamous cell carcinoma of the head and neck: a randomized, open-label, phase IIb, 5-year study in Indian patients. Oral Oncol. (2014) 50:498-505. doi: 10.1016/j.oraloncology.2013. 11.008

63. Patil VM, Noronha V, Joshi A, Agarwal J, Ghosh-Laskar S, Budrukkar A, et al. A randomized phase 3 trial comparing nimotuzumab plus cisplatin chemoradiotherapy versus cisplatin chemoradiotherapy alone in locally advanced head and neck cancer. Cancer. (2019) 125:318497. doi: $10.1002 /$ cncr.32179
64. Vega A, Vila L, Venereo P, Valls A, De Armas E, Romero M, et al. Safety and effectiveness of nimotuzumab in the treatment of advanced head and neck cancer patients. Phase IV clinical trial: final results. JJ Cancer Sci Res. (2019) 4:057.

65. Mackiewicz J, Rybarczyk-Kasiuchnicz A, Łasinska I, Mazur-Roszak M, Swiniuch D, Michalak M, et al. The comparison of acute toxicity in 2 treatment courses: three-weekly and weekly cisplatin treatment administered with radiotherapy in patients with head and neck squamous cell carcinoma. Medicine. (2017) 96:e9151. doi: 10.1097/MD.0000000000 009151

66. Mohamed A, Twardy B, Zordok MA, Ashraf K, Alkhoder A, Schrapp $\mathrm{K}$, et al. Concurrent chemoradiotherapy with weekly versus triweekly cisplatin in locally advanced squamous cell carcinoma of the head and neck: comparative analysis. Head Neck. (2019) 41:1490-8. doi: 10.1002/hed. 25379

67. Szturz P, Wouters K, Kiyota N, Tahara M, Prabhash K, Noronha $\mathrm{V}$, et al. Low-Dose vs. high-dose cisplatin: lessons learned from 59 chemoradiotherapy trials in head and neck cancer. Front Oncol. (2019) 9:86. doi: 10.3389/fonc.2019.00086

68. Guan J, Zhang Y, Li Q, Zhang Y, Li L, Chen M, et al. A meta-analysis of weekly cisplatin versus three weekly cisplatin chemotherapy plus concurrent radiotherapy (CRT) for advanced head and neck cancer (HNC). Oncotarget. (2016) 7:70185-93. doi: 10.18632/oncotarget.11824

69. Jacinto JK, Co J, Mejia MB, Regala EE. The evidence on effectiveness of weekly vs triweekly cisplatin concurrent with radiotherapy in locally advanced head and neck squamous cell carcinoma (HNSCC): a systematic review and meta-analysis. Br J Radiol. (2017) 90:1079. doi: 10.1259/bjr.20 170442

70. Bauml JM, Vinnakota R, Anna Park YH, Bates SE, Fojo T, Aggarwal C, et al. Cisplatin every 3 weeks versus weekly with definitive concurrent radiotherapy for squamous cell carcinoma of the head and neck. J Natl Cancer Inst. (2019) 111:490-7. doi: 10.1093/jnci/djy133

71. Lee SY, Choi YS, Song IC, Park SG, Keam B, Yang YJ, et al. Comparison of standard-dose 3-weekly cisplatin and low-dose weekly cisplatin for concurrent chemoradiation of patients with locally advanced head and neck squamous cell cancer: a multicenter retrospective analysis. Medicine. (2018) 97:e10778. doi: 10.1097/MD.0000000000 010778

72. Helfenstein S, Riesterer O, Meier UR, Papachristofilou A, Kasenda B, Pless $M$, et al. 3-weekly or weekly cisplatin concurrently with radiotherapy for patients with squamous cell carcinoma of the head and neck - a multicentre, retrospective analysis. Radiat Oncol. (2019) 14:32. doi: 10.1186/s13014-019-1235-y

73. Vermorken JB, Mesia R, Rivera F, Remenar E, Kawecki A, Rottey $\mathrm{S}$, et al. Platinum-based chemotherapy plus cetuximab in head and neck cancer. N Engl J Med. (2008) 359:1116-27. doi: 10.1056/NEJMoa0 802656

74. National Comprehensive Cancer Network (NCCN). NCCN Clinical Practice Guidelines in Oncology. Head and Neck Cancers Version 1.2020. National Comprehensive Cancer Network. Available online at https://www.nccn. org/professionals/physician_gls/pdf/head-and-neck.pdf (accessed March 03, 2020).

75. Bonner JA, Harari PM, Giralt J, Azarnia N, Shin DM, Cohen RB, et al. Radiotherapy plus cetuximab for squamous-cell carcinoma of the head and neck. N Engl J Med. (2006) 354:567-7. doi: 10.1056/NEJMoa 053422

76. Mehanna H, Robinson M, Hartley A, Kong A, Foran B, Fulton-Lieuw $\mathrm{T}$, et al. Radiotherapy plus cisplatin or cetuximab in low-risk human papillomavirus-positive oropharyngeal cancer (De-ESCALaTE HPV): an open-label randomised controlled phase 3 trial. Lancet. (2019) 393:5160. doi: 10.1016/S0140-6736(18)32752-1

77. Gillison ML, Trotti AM, Harris J, Eisbruch A, Harari PM, Adelstein DJ, et al. Radiotherapy plus cetuximab or cisplatin in human papillomavirus-positive oropharyngeal cancer (NRG Oncology RTOG 1016): a randomised, multicentre, non-inferiority trial. Lancet. (2019) 393:40-50. doi: 10.1016/S0140-6736(18)32779-X

78. Magrini SM, Buglione M, Corvò R, Pirtoli L, Paiar F, Ponticelli P, et al. Cetuximab and radiotherapy versus cisplatin and radiotherapy for locally 
advanced head and neck cancer: a randomized phase II trial. J Clin Oncol. (2016) 34:427-35. doi: 10.1200/JCO.2015.63.1671

79. Ang KK, Zhang Q, Rosenthal DI, Nguyen-Tan PF, Sherman EJ, Weber RS, et al. Randomized phase III trial of concurrent accelerated radiation plus cisplatin with or without cetuximab for stage III to IV head and neck carcinoma: RTOG 0522. J Clin Oncol. (2014) 32:2940-50. doi: 10.1200/JCO.2013.5 3.5633

80. Mesía R, Henke M, Fortin A, Minn H, Yunes Ancona AC, Cmelak A, et al. Chemoradiotherapy with or without panitumumab in patients with unresected, locally advanced squamous-cell carcinoma of the head and neck (CONCERT-1): a randomised, controlled, open-label phase 2 trial. Lancet Oncol. (2015) 16:208-20. doi: 10.1016/S1470-2045(14)7 1198-2

81. Qureishi A, Rieunier G, Shah KA, Aleksic T, Winter SC, Møller H, et al. Radioresistant laryngeal cancers upregulate type 1 IGF receptor and exhibit increased cellular dependence on IGF and EGF signalling. Clin Otolaryngol. (2019) 44:1026-36. doi: 10.1111/coa.13434

82. Bonner J, Giralt J, Harari P, Spencer S, Schulten J, Hossain A, et al. Cetuximab and radiotherapy in laryngeal preservation for cancers of the larynx and hypopharynx: a secondary analysis of a randomized clinical trial. JAMA Otolaryngol Head Neck Surg. (2016) 142:842-9. doi: 10.1001/jamaoto.2016.1228
Conflict of Interest: The authors declare that the clinical trials described here-in received funding from the Center of Molecular Immunology, Cuba, the Cuban Ministry of Public Health, YMBiosciences (Canada), Biocon LTD (India), and the TATA Memorial Center Research Administration Council (India). YMBiosciences, Biocon LTD and the TATA Memorial Center Research Administration Council were not involved in this paper design, collection, analysis, interpretation of data, writing of this article or the decision to submit it for publication Three authors (TC, ZM, NI) currently work or have worked for the Center of Molecular Immunology, the institution that owns the patent and manufactures nimotuzumab. NI was employed later by Biocubafarma.

The remaining author declares that the research was conducted in the absence of any other commercial or financial relationships that could be construed as a potential conflict of interest.

Copyright $\odot 2020$ Crombet Ramos, Mestre Fernández, Mazorra Herrera and Iznaga Escobar. This is an open-access article distributed under the terms of the Creative Commons Attribution License (CC BY). The use, distribution or reproduction in other forums is permitted, provided the original author(s) and the copyright owner $(s)$ are credited and that the original publication in this journal is cited, in accordance with accepted academic practice. No use, distribution or reproduction is permitted which does not comply with these terms. 